\title{
Prediction and management of nocturnal hypoglycaemia in diabetes
}

\author{
G WHINCUP AND R D G MILNER \\ Department of Paediatrics, University of Sheffield, The Children's Hospital, Sheffield
}

SUMmaRY Blood glucose measurement's were made at 2200,0200 , and $0800 \mathrm{~h}$ in 102 children with diabetes during a 24 hour planned admission to hospital. Nocturnal hypoglycaemia $(<3 \cdot 0$ $\mathrm{mmol} / \mathrm{l})$ occurred in 24 of $71(34 \%)$ children on twice daily insulin and in three of $31(10 \%)$ children on once daily insulin. Predictive value modelling showed that a blood glucose concentration of less than $7 \mathrm{mmol} / \mathrm{l}$ at $2200 \mathrm{~h}$ was the best predictor of nocturnal hypoglycaemia, with a sensitivity of $63 \%$, specificity of $94 \%$, and positive and negative predictive values of $83 \%$. Blood glucose measurement at $0800 \mathrm{~h}$ had no predictive value for nocturnal hypoglycaemia. The mean (SD) glycosylated haemoglobin concentration of children on twice daily insulin who had nocturnal hypoglycaemia was $55(8) \mathrm{mmol} \mathrm{HMF} / \mathrm{mol} \mathrm{Hb}$, which was significantly less than that of children on twice daily insulin who did not have hypoglycaemia $(64$ (11) $\mathrm{mmol} \mathrm{HMF} / \mathrm{mol} \mathrm{Hb})$ or those on once daily insulin (62 (11) $\mathrm{mmol} \mathrm{HMF} / \mathrm{mol} \mathrm{Hb})$. A controlled trial was then performed in which 29 children with diabetes who had a blood glucose concentration at $2200 \mathrm{~h}$ of $<7 \mathrm{mmol} / \mathrm{l}$ measured by Reflocheck were randomised into two groups, one of which received $10 \mathrm{~g}$ carbohydrate supplement and the other of which did not. Thirteen of the 14 children in the control group had hypoglycaemia at $0200 \mathrm{~h}$, whereas the snack prevented hypoglycaemia in 12 of 15 in the test group. Blood glucose values in the two groups at $0800 \mathrm{~h}$ were similar. We conclude that bedtime glucose measurement in children on twice daily insulin is a useful predictor for nocturnal hypoglycaemia, which can be prevented by a small carbohydrate snack in those at risk.

Unrecognised nocturnal hypoglycaemia may be a widespread and important problem in children with diabetes and is certainly a phenomenon that is difficult to detect. Failure to recognise nocturnal hypoglycaemia in adults has been reported to lead to transient hemiparesis, ${ }^{1}$ organic personality syndrome ${ }^{2}$ and a syndrome masquerading as senile dementia. ${ }^{3}$ Attempts to identify individuals at risk have included the measurement of early morning blood glucose concentrations ${ }^{4}$ or overnight urinary cortisol concentrations. ${ }^{5}$ Recently, Pramming et al reported that nocturnal hypoglycaemia may be predicted with reasonable accuracy in adults with diabetes by the measurement of an evening blood glucose concentration at $2300 \mathrm{~h} .^{6}$

Nocturnal hypoglycaemia in children with diabetes has been studied, but less than in adults. ${ }^{7-9}$ A frequency of $10-19 \%$ has been reported in

Conversion: for $\mathrm{HbA}_{\mathrm{lc}}$ by electrophoresis, $1 \mathrm{mmol} \mathrm{HMF} / \mathrm{mol}$ $\mathrm{Hb}=0 \cdot 19 \%$; for $\mathrm{HbA}_{1 \mathrm{c}}$ by column chromatography, $1 \mathrm{mmol}$ $\mathrm{HMF} / \mathrm{mol} \mathrm{Hb}=0 \cdot 21 \%$ children treated with twice daily insulin, ${ }^{89}$ and it has been claimed that one consequence of unrecognised nocturnal hypoglycaemia has been overtreatment with insulin. ${ }^{7}$ The present study assessed the prevalence of nocturnal hypoglycaemia in a sample of children with diabetes and tested the value of bedtime blood glucose measurements as a predictor of nocturnal hypoglycaemia in children who eat and go to bed earlier than adults and who were treated with insulin once or twice daily. The effect of a small bedtime carbohydrate snack in preventing hypoglycaemia in those at risk was then evaluated in a controlled trial.

\section{Patients and methods}

Patients. There were two phases: (1) the prevalence and prediction study, which took place from January 1983 to January 1984, and (2) the intervention study, which took place from January to August 1984. The subjects were children admitted to hospital for annual review of their diabetic control. 
They were aged 3 to 16 years and all had had diabetes for more than one year. No child had symptoms of nocturnal hypoglycaemia and all were clinically well when admitted between 1000 and $1300 \mathrm{~h}$ for a 24 hour stay in hospital. The admission helped to standardise the times of insulin injection and food intake and the amount of exercise taken. Carbohydrate intake followed the recommendations of the British Diabetic Association, with about $50 \%$ being rich in polysaccharides. The last food intake was 90 minutes before the bedtime blood sample was taken, which was collected at about $2200 \mathrm{~h}$. Further samples were collected at $0200 \mathrm{~h}$ and $0800 \mathrm{~h}$. No child woke at $0200 \mathrm{~h}$ due to blood sampling. Some children were studied in each phase.

\section{Prevalence and prediction study}

There were 102 children in the prevalence and prediction study. Seventy one were receiving twice daily insulin mixtures; 32 took Monotard/Actrapid (Novo) and 39 took Humulin Isophane/Soluble (Lilly). The daily total insulin dose was similar in the two groups, being 0.62-2.50 U/kg (mean $1.01 \mathrm{U} / \mathrm{kg}$ ) and $0.40-1.54 \mathrm{U} / \mathrm{kg}$ (mean $0.93 \mathrm{U} / \mathrm{kg}$ ), respectively. Thirty one took a long acting insulin or an insulin mixture once daily in a dose ranging from 0.25 to $1.35 \mathrm{U} / \mathrm{kg}$ (mean $0.90 \mathrm{U} / \mathrm{kg}$ ).

\section{Intervention study}

There were 97 children in the intervention study. Twenty nine $(30 \%)$ had a blood glucose concentration of $<7.0 \mathrm{mmol} / \mathrm{l}$ at $220(0 \mathrm{~h}$ measured by Reflocheck (Boeringer, Mannheim). They were randomised into two groups: (1) the control group (10 boys and four girls), which received no carbohydrate supplement, and (2) the test group (nine boys and six girls), which received $10 \mathrm{~g}$ carbohydrate as soon as the low bedtime blood glucose result was known. Twenty one children received twice daily insulin and eight received single dose treatment in the morning. All children in both studies had a $20 \mathrm{~g}$ carbohydrate snack at $2015 \mathrm{~h}$ and those on twice daily insulin had their evening dose 20 minutes before the main meal at $1715 \mathrm{~h}$.

Methods. Fingertip heparinised blood samples were taken from all children at 2200,0200 , and $0800 \mathrm{~h}$ and stored at $4^{\circ} \mathrm{C}$ until analysed for glucose by the hexokinase method ${ }^{11}$ later in the day. In the intervention study blood glucose concentration was also measured at the bedside by Reflocheck (Boeringer, Mannheim).

Glycosylated haemoglobin $\left(\mathrm{HbA}_{\mathrm{lc}}\right.$ ) (normal range $29-39 \mathrm{mmol} \mathrm{HMF} / \mathrm{mol} \mathrm{Hb}$ ) was measured in all children during admission by a colorimetric assay, ${ }^{11}$ and mean $\mathrm{HbA}_{\mathrm{lc}}$ concentrations in different groups were compared by Student's unpaired $t$ test. For the purpose of this study nocturnal hypoglycaemia was defined as a blood glucose concentration of less than $3 \mathrm{mmol} / \mathrm{l}$.

Results were analysed using the predictive value model, ${ }^{12}$ employing the following definitions.

(1) Sensitivity: the proportion of children with nocturnal hypoglycaemia at $0200 \mathrm{~h}$ with a blood glucose concentration less than a given value at $2200 \mathrm{~h}$.

(2) Specificity: the proportion of children without nocturnal hypoglycaemia at $0200 \mathrm{~h}$ with a blood glucose concentration greater than a given value at $2200 \mathrm{~h}$.

(3) Positive predictive value: the proportion of children with a blood glucose concentration less than a given value at $2200 \mathrm{~h}$ who also had nocturnal hypoglycaemia at $0200 \mathrm{~h}$.

(4) Negative predictive value: the proportion of children with a blood glucose concentration greater than a given value at $2200 \mathrm{~h}$ who did not have nocturnal hypoglycaemia at $0200 \mathrm{~h}$.

\section{Results}

\section{Prevalence and prediction study.}

Twice daily insulin

The blood glucose concentration fell to less than $3 \cdot()$ $\mathrm{mmol} / \mathrm{l}$ at $0200 \mathrm{~h}$ in 24 of the 71 children $(34 \%)$. Ten of the children with hypoglycaemia had received Monotard/Actrapid mixtures and 14 had received Humulin Isophane/Soluble mixtures.

The positive predictive values of blood glucose concentrations of less than $5,6,7,8,9$, and 10 $\mathrm{mmol} / \mathrm{l}$ at $2200 \mathrm{~h}$ for nocturnal hypoglycaemia at $0200 \mathrm{~h}$ are shown in Table 1 , from which it can be seen that the best predictor was a blood glucose concentration of less than $7 \mathrm{mmol} / \mathrm{l}$ at $2200 \mathrm{~h}$, which had both a positive and a negative predictive value of $83 \%$, a sensitivity of $63 \%$, and specificity of $94 \%$. More explicitly, 18 children had a blood glucose concentration less than $7 \mathrm{mmol} / \mathrm{l}$ at $2200 \mathrm{~h}$, and of

Table 1 Predictive value models for nocturnal hypoglycaemia at 0200 h from different blood glucose concentrations at $2200 \mathrm{~h}$

\begin{tabular}{lllll}
\hline $\begin{array}{l}\text { Blood glucose } \\
\text { (mmol/) }\end{array}$ & Somsitivity & Specificity & Predictive value \\
at 22(6)h & & & Positive & Negative \\
\hline$<5$ & 42 & 96 & 83 & 76 \\
$<6$ & 54 & 94 & 81 & 80 \\
$<7$ & 63 & 94 & 83 & 83 \\
$<8$ & 75 & 81 & 69 & 87 \\
$<9$ & 83 & 81 & 71 & 91 \\
$<10$ & 92 & 74 & 65 & 95 \\
\hline
\end{tabular}


these, $15 \mathrm{had}$ a concentration of less than $3 \mathrm{mmol} / \mathrm{l}$ at $0200 \mathrm{~h}$. Fifty three children had a blood glucose concentration of more than $7 \mathrm{mmol} / \mathrm{l}$ at $2200 \mathrm{~h}$, and of these, nine had a concentration of less than 3 $\mathrm{mmol} / \mathrm{l}$ at $0200 \mathrm{~h}$. The relation between the blood glucose concentration at $2200 \mathrm{~h}$ and the change in blood glucose from $2200 \mathrm{~h}$ to $0200 \mathrm{~h}$ is shown in the Figure. In eight of the 24 children with nocturnal hypoglycaemia the blood glucose concentration at $0200 \mathrm{~h}$ was less than $2 \mathrm{mmol} / \mathrm{l}$. The mean (SD) blood glucose concentration at $0800 \mathrm{~h}$ of the children who had nocturnal hypoglycaemia was significantly lower $(10.0(6.9) \mathrm{mmol} / \mathrm{l})$ than that of those who had not $(13.6(5.9) \mathrm{mmol} / \mathrm{l})$. Similarly, the mean (SD) $\mathrm{HbA}_{\mathrm{Ic}}$ concentration of the children with nocturnal hypoglycaemia was significantly less than that of those with no nocturnal hypoglycaemia (55 (8) $v 64$ (11) $\mathrm{mmol} \mathrm{HMF} / \mathrm{mol} \mathrm{Hb}$ ). The predictive value of

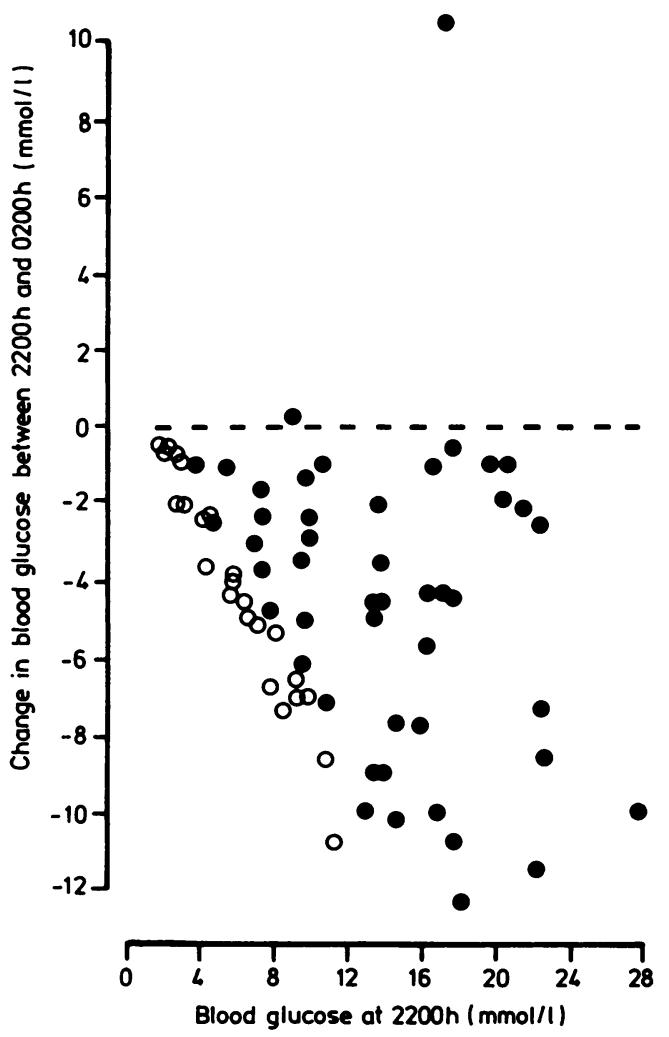

Figure Blood glucose concentration at 2200h correlated with change in blood glucose between 2200h and $0200 \mathrm{~h}$ in 71 children with diabetes taking twice daily insulin. Children with blood glucose concentrations of more than $3.0 \mathrm{mmol} / \mathrm{l}$ at $0200 \mathrm{~h}$ are shown by solid circles and those with concentrations of less than $3.0 \mathrm{mmol} / \mathrm{l}$ at $0200 \mathrm{~h}$ by open circles. blood glucose measurements at $0800 \mathrm{~h}$ for nocturnal hypoglycaemia the previous night was no better than chance (results not shown).

\section{Once daily insulin}

Three of the 31 children who received once daily insulin developed nocturnal hypoglycaemia. The number was too small for comparison with those receiving twice daily insulin. The mean (SD) $\mathrm{HbA}_{\mathrm{lc}}$ concentration of the 28 children who did not have nocturnal hypoglycaemia was 62 (11) mmol $\mathrm{HMF} /$ mol $\mathrm{Hb}$, which was very similar to that of the 47 children on twice daily insulin who did not have nocturnal hypoglycaemia.

\section{Glycosylated haemoglobin}

There was no correlation between the blood glucose concentration at $0200 \mathrm{~h}$ and the $\mathrm{HbA}_{\mathrm{lc}}$ concentration in any subgroup or in the total study sample.

Intervention study. In all cases the laboratory measurement of blood glucose confirmed the Reflocheck estimate at $0200 \mathrm{~h}$ of $<7 \mathrm{mmol} / \mathrm{l}$. The mean (range) of the laboratory determinations was $3.8(1.6$ to 6.0$) \mathrm{mmol} / \mathrm{l}$. Results were analysed, taking account of whether the children had insulin once or twice a day (Table 2).

Twice daily insulin

Ten of the 11 children in the control group had hypoglycaemia at $0200 \mathrm{~h}$, whereas only two of the 10 in the test group had a blood glucose concentration of $<3.0 \mathrm{mmol} / \mathrm{l}$ at $0200 \mathrm{~h}$. The blood glucose concentration fell between 2200 and $0200 \mathrm{~h}$ in every child in the control group, whereas the concentration rose in eight of the children in the test group, but one of these had hypoglycaemia at $0200 \mathrm{~h}$ notwithstanding. By $0800 \mathrm{~h}$ a similar mean rise in

Table 2 Blood glucose concentrations at 2200h and change in blood glucose at $0200 \mathrm{~h}$ and $0800 \mathrm{~h}$ in children with diabetes at risk of nocturnal hypoglycaemia. Values are mean (SEM)

\begin{tabular}{|c|c|c|c|c|}
\hline \multirow[t]{2}{*}{ Patient group } & \multirow[t]{2}{*}{$(n=)$} & \multicolumn{3}{|c|}{$\begin{array}{l}\text { Blood glucose or change in blood glucose } \\
\text { (mmol/l) }\end{array}$} \\
\hline & & $2200 h$ & $0200 h$ & $080 \% h$ \\
\hline \multicolumn{5}{|l|}{ Twice daily insulin } \\
\hline Bedtime carbohydrate & $(10)$ & $3.2(0.4)$ & $+0.9(0.4)$ & $+7.9(1.4)$ \\
\hline No carbohydrate & (11) & $4 \cdot 0(0 \cdot 5)$ & $-2 \cdot 0(0 \cdot 4)^{* *}$ & $+7 \cdot 6(2 \cdot 6)$ \\
\hline \multicolumn{5}{|l|}{ Once daily insulin } \\
\hline Bedtime carbohydrate & $(5)$ & $3 \cdot 8(0 \cdot 2)$ & $+2 \cdot 1(1 \cdot 3)$ & $+3.5(1.8)$ \\
\hline No carbohydrate & (3) & $4 \cdot 8(0 \cdot 8)$ & $-1.9(0.6)^{*}$ & $+5.7(0.7)$ \\
\hline \multicolumn{5}{|l|}{ All patients } \\
\hline Bedtime carbohydrate & $(15)$ & $3.4(0 \cdot 3)$ & $+1.3(0.5)$ & $+6.3(1.2)$ \\
\hline No carbohydrate & (14) & $4 \cdot 2(0 \cdot 4)$ & $-2 \cdot 0(0 \cdot 3)^{* *}$ & $+7 \cdot 1(1.9)$ \\
\hline
\end{tabular}

${ }^{*} \mathrm{p}<0.05,{ }^{* *} \mathrm{p}<(0.01$ by Student's $t$ test 
blood glucose concentration of $7-8 \mathrm{mmol} / 1 \mathrm{had}$ occurred in both groups, but the range of change was greater in the control patients, suggesting that a Somogyi effect might have occurred in some.

\section{Once daily insulin}

There were fewer patients taking insulin once daily, reflecting current clinical practice. There had been a fall in blood glucose concentration at $0200 \mathrm{~h}$ in all three of the control patients, and two became asymptomatically hypoglycaemic. In all five test patients the blood glucose concentration had risen at $0200 \mathrm{~h}$. The mean rise in blood glucose concentration at $0800 \mathrm{~h}$ in both groups was similar but less than that seen in patients taking twice daily insulin.

\section{Glycosylated haemoglobin}

The quality of diabetic control as reflected in the $\mathrm{HbA}_{1 \mathrm{c}}$ measurements ranged from 39 to $60 \mathrm{mmol}$ $\mathrm{HMF} / \mathrm{mol} \mathrm{Hb}$ but was similar in all four subgroups, mean (SD) values (in mmol $\mathrm{HMF} / \mathrm{mol} \mathrm{Hb}$ ) being 53 (6) in test patients on twice daily insulin, 47 (5) in control patients on twice daily insulin, $55(3)$ in test patients on once daily insulin, and 52 (9) in control patients on once daily insulin.

\section{Discussion}

This project was designed to measure the prevalence of nocturnal hypoglycaemia in children with diabetes with minimum inconvenience under relatively standardised conditions, which were thought to favour hyperglycaemia rather than hypoglycaemia because of the relative inactivity associated with admission to hospital. A blood glucose concentration of $3 \mathrm{mmol} / \mathrm{l}$ was used as a working definition of hypoglycaemia based on previous work and $0200 \mathrm{~h}$ was chosen as the sampling time because of the authors' previous experience in diabetic summer camps where most symptomatic hypoglycaemia occurred between 0100 and $0300 \mathrm{~h}$.

About one third of the children taking insulin twice daily experienced symptomatic nocturnal hypoglycaemia, and among these one third had severe hypoglycaemia with a blood glucose concentration of less than $2 \mathrm{mmol} / \mathrm{l}$. In contrast, only one tenth of the children receiving insulin once a day experienced nocturnal hypoglycaemia. If the three subgroups, twice daily insulin with or without hypoglycaemia and once daily insulin without hypoglycaemia, were considered the quality of diabetic control judged by $\mathrm{HbA}_{1 \mathrm{c}}$ concentrations was indifferent to poor and was similar in the two subgroups without hypoglycaemia, whereas the patients experiencing hypoglycaemia had a significantly lower mean $\mathrm{HbA}_{1 \mathrm{c}}$ concentration, although there was no direct correlation between $\mathrm{HbA}_{1 \mathrm{c}}$ and blood glucose concentrations at $0200 \mathrm{~h}$ within this subgroup. This is not surprising as the $\mathrm{HbA}_{\mathrm{lc}}$ reflects long term overall glucose homeostasis and the measurement of blood glucose at $0200 \mathrm{~h}$ took place on one night only. A legitimate inference is that patients with lower $\mathrm{HbA}_{\mathrm{lc}}$ concentrations taking insulin twice daily are more prone to nocturnal hypoglycaemia. Should this cause concern or be regarded merely as an epiphenomenon? In favour of the latter view is that the children were clinically well at the time of study and the hypoglycaemia, by definition, was asymptomatic. Against this is the evidence that nocturnal hypoglycaemia in adults can damage the brain, and it is plausible to suggest that the effect is more likely to be gradual and cumulative rather than abrupt. Anecdotally, two of the children in the present study subsequently had transient hemiparesis and a third had early morning convulsions, all as complications of nocturnal hypoglycaemia. All three children had $\mathrm{HbA}_{1 \mathrm{c}}$ concentrations below $50 \mathrm{mmol} \mathrm{HMF} / \mathrm{mol} \mathrm{Hb}$ at the time and were perceived to have excellent diabetic control.

While this study may have fuelled the debate on what is optimal control for a child with diabetes without providing a clear answer to that question, it has also clarified ways in which nocturnal hypoglycaemia may be predicted. Analysis of bedtime and early morning blood glucose concentrations has shown clearly that a bedtime concentration of less than $7 \mathrm{mmol} / \mathrm{l}$ is a useful predictor that hypoglycaemia will occur. This is in keeping with the observation of Pramming et al that $80 \%$ of adults on twice daily insulin with a blood glucose concentration of less than $6 \mathrm{mmol} / \mathrm{l}$ at $2300 \mathrm{~h}$ had nocturnal hypoglycaemia. ${ }^{6}$ We were unable to find any association between nocturnal hypoglycaemia and subsequent blood glucose concentrations measured at $0800 \mathrm{~h}$, which contrasts with an earlier report. ${ }^{8}$

The simple intervention study confirmed that bedtime glucose monitoring with the Reflocheck overestimated blood glucose concentrations in the low and low-normal glycaemic range ${ }^{13}$ but was none the less useful in predicting which children would experience nocturnal hypoglycaemia. More importantly, we have shown that this risk can be ameliorated by a $10 \mathrm{~g}$ carbohydrate snack without prejudice to the overall quality of diabetic control as reflected in the $0800 \mathrm{~h}$ blood glucose reading. We think that this simple procedure is worth recommending to families for use at home, in particular in those cases where there may be cause to suspect that nocturnal hypoglycaemia is occurring in the child with diabetes.

Ideally, each child should have been studied on 
more than one occasion and acted as a self control. We did not consider it justificd to admit a child to hospital more than once and preferred to use a less elegant experimental model but one that was ethically more acceptable. Normal bedtime for the children in this study was from 2030 to $2200 \mathrm{~h}$, and the blood glucose testing and carbohydrate supplementation did not change this routine, but care was taken to ensure that those who had extra carbohydrate at $2200 \mathrm{~h}$ cleaned their teeth.

We are grateful to the Chemical Pathology Service of the Children ‘s Hospital and Royal Hallamshire Hospital for measuring blood glucose and glycosylated haemoglobin concentrations.

\section{References}

1 Silas JH, Grant DS, Maddocks JL. Transient hemiparetic attacks duc to unrecognised nocturnal hypoglycaemia. $\mathrm{Br}$ Med $\mathrm{J}$ 1981:282:132-3.

2 Krahm DD, Mackenzie TB. Organic personality syndrome caused by insulin-related nocturnal hypoglycaemia. Psychosomatics 1984:25:711-2.

${ }^{3}$ Ramasmy R. Unrecognised nocturnal hypoglycaemia masquerading as senile dementia. Postgrad Med J 1983;59: $575-7$.
+ Unger RH. Nocturnal hypoglycacmia in aggressively controlled diabetics. $N$ Engl Med J 1982;306:1294.

5 Moore RA. Smith RF. Asplin CM. Sample test for nocturnal hypoglycaemia in diabetic patients. Lancet 1979;ii:409-10.

- Pramming S. Thorsteinsson B. Bendtson I, Ram B. Binder C. Nocturnal hypoglycaemia in patients receiving conventional treatment with insulin. Br Med $J$ 1985:291:376-9.

7 Rosenbloom AL. Giordane BP. Chronic overtreatment with insulin in children and adolescents. Am J Dis Child 1977;131: $881-5$.

8 Winter RJ. Profiles of metablic control in diabetic childrenfrequency of asymptomatic nocturnal hypoglycaemia. Metabolism 1981:30:666-72.

9 Baumer JH, Edelstein AD, Howlett BC, Owens C, Pennock CA. Savage DCL. Impact of home blood glucose monitoring on childhood diabetes. Arch Dis Child 1982:57:195-9.

10 Bender RJL. Mead DC. Evaluation of glucose 6 phosphate dehydrogenase from legonostoc mesenteroids in the hexokinase method for determining glucose in serum. Clin Chem 1974:20:586-90.

"Fluckiger R. Winterhatter KH. In vitro synthesis of hacmoglobin Alc. FEBS Lett 1976:71:356.

12 Vechio TJ. Predictive value of a single diagnostic test in unselected populations. N Engl J Med 1966;274:1171-3.

13 Southgate HJ, Marks V. Measurement of hypoglycaemia by Reflocheck. Practical Diabetes 1986;3:206-7.

Correspondence to Professor R D G Milner. Department of Paediatrics. The Children`s Hospital. Sheffield S10 2TH. England.

Received 18 November 1986 